day before meals she is taking approximately one-fiftieth of the dose given the experimental rabbits.

This laboratory experiment would not prove that cyclizine hydrochloride is a teratogenic compound in humans. It must be remembered that it is experimentally proved that cleft palate or skeletal defects can be produced by dietary deficiencies, hypervitaminosis A, anoxia, or cortisone. However, too literal a transference of the experimental results to man may be misleading ; we may find many compounds which cause abnormalities when taken in 50 times the normal dose may be perfectly harmless when taken in normal or in a slightly excessive dosage.- I am, etc.,

$$
\begin{aligned}
& \begin{array}{l}
\text { Sydney, N.S.W., } \\
\text { Australia. } \\
\text { Reference }
\end{array} \\
& { }^{1} \text { Tuchmann-Duplessis, H., C.R. Acad. Sci. (Paris), in press. }
\end{aligned}
$$

\section{Treatment of Sickle-cell Anaemia}

SIR,-I have been asked by colleagues from abroad to explain the rationale of the alkali/magnesium régime which I have recommended over the last three years for individual cases of sickle-cell anaemia. I am asking you, therefore, for the hospitality of your columns to furnish this explanation to a wider public.

Sickle-cell anaemia has two deleterious aspects: haemolytic anaemia and infarctive crises. The first is usually no more severe than many other congenital and acquired haemolytic anaemias which seem to be compatible with a sheltered existence. It requires careful protection particularly from infections, and, as is now generally recognized, subsidiary doses of folic acid (5 mg. b.d.) to assist the more than normal haemopoietic activity of the bone marrow in these conditions. Aplastic crises are a special danger, but the problem they represent does not differ from that of other haemolytic anaemias.

Sickle-cell disease, which, besides the homozygous sickle-cell anaemia, includes the modified sickle-cell anaemias such as sickle-cell-haemoglobin $\mathrm{C}$ disease and sickle-cell thalassaemia, is, however, especially dangerous because of the infarctive crises. The cells take on the abnormal sickle-shape when they are deoxygenated. The dangerous degree of deoxygenation is rarely achieved in sickle-cell trait in which the abnormal haemoglobin amounts to less than $50 \%$ of the corpuscular haemoglobin. To bring about intravascular sickling, conditions have to be quite exceptional, and if sickle-cell trait carriers are afflicted they usually belong to that group in which the proportion of haemoglobin $\mathrm{S}$ amounts to about $40 \%$ rather than $30 \%$ or less. In sickle-cell disease the degree of deoxygenation necessary for intravascular sickling may occur under more usual conditions. There are, however, three important factors without which infarctive crises do not occur: (1) local acidosis, (2) stasis, and (3) a firm intravascular wedging of the sickled blood.

(1) There have been numerous references to the effect of acidosis on sickling; the most relevant study is that by Greenberg and Kass. ${ }^{1}$ Physicians have used an alkali régime in the treatment of sickle-cell anaemia for some time (see, for example, Nwokolo ${ }^{2}$ and Scott and Ferguson $^{3}$ ). In my view, alkali treatment has its place in the prevention of sickling rather than in the treatment of a crisis, where its role is that of preventing further sickling rather than of affecting the wedging of the already sickled cells.
(2) The time factor has been pointed out by Allison. ${ }^{4}$ If a cell has been deoxygenated in the venous circulation it will normally be reoxygenated in the lungs before the 15 seconds or so have passed which are required for the physical process of sickling. However, if there is stasis, sickling of cells will take place. This will happen from time to time, and it will depend on the length of stay in the venous circulation as well as on the alkali reserve of the blood. Stationary blood loses oxygen and acquires $\mathrm{H}_{2} \mathrm{CO}_{3}$ and other acid metabolites. The greater the alkali reserve, the longer will the stasis have to last to result in sickling.

Even if such intravascular sickling has taken place, infarctive crises do not necessarily arise. The sludged sickled cells can be washed from the smaller veins into the larger branches, and there mix with other cells and then circulate freely. Evidence of this is indeed often seen in the direct smear of the peripheral blood of such patients.

(3) For a painful and lasting crisis a third factor is necessary - the cells have to be bound together by clotting plasma. It is here where an intravenous injection of magnesium sulphate can delay the increase in viscosity. The theoretical and experimental background for the magnesium treatment has been previously described. ${ }^{5} 6$

Even if clotting has taken place, magnesium can prevent further strengthening of the clot, and will thus allow its gradual reduction and resolution with a dispersal into the larger veins. In addition magnesium has a transient vasodilatory effect which results in some relief of pain in the congested area.

Experiences of clinical colleagues at this hospital and elsewhere have so far been limited, but they already justify further continuation of magnesium therapy, and an extended trial which can best be carried out at one of the larger hospitals in Africa, the West Indies, or Southern States of the U.S.

The following is a tentative régime. In an acute crisis inject $50 \%$ magnesium sulphate intravenously within 40-60 seconds, $1 \mathrm{ml}$. for small children, $2 \mathrm{ml}$. for adolescents and adults. It is obvious that other more traditional measures such as the treatment of infections and keeping the patient warm remain as important as before. The injection is repeated four to six hourly until the crisis has passed. It may be found convenient to establish a glucose drip and to inject into the tubing. When the crisis has passed magnesium treatment is continued by mouth for another three to six days. Seventy per cent. magnesium glutamate $\left(=6 \% \mathrm{Mg}^{++}\right)$ is given four to six hourly between meals- $-5 \mathrm{ml}$. for small children, and 7-10 ml. for adolescents and adults, diluted to $30 \mathrm{ml}$. with water. It is important to give the magnesium glutamate between meals because the presence of other cations interferes with the absorption of the magnesium. If the dosage given causes stools to become too loose, it should be reduced by $10-20 \%$.

Following the magnesium treatment the patient is put on a sodium bicarbonate régime. This has to be worked out individually, and the aim is to give enough to keep the urine sufficiently alkaline to give a blue reaction with litmus paper. A good alkali reserve will then protect the cells from sickling if there is the occasional stasis with deoxygenation. This régime requires the constant testing of the urine with litmus paper and can be carried out by the family or by the patient. It is important that the bicarbonate dosage is raised as soon as the urine becomes acid, which is particularly the case in infections. If at any time there is difficulty in preventing acidosis, it is safer to return for a week or so to magnesium by mouth. Magnesium injections may also be given as a preventive measure when there are potentially dangerous episodes such as an acute pneumonia, or 
immediately after delivery. Provided the kidney function is normal the bicarbonate treatment can be carried on indefinitely, and in any case there can be very few disadvantages of such a treatment which are not outweighed by the prevention of crises.

Despite the fact that this treatment has been in use over several years the number of patients treated at this and other hospitals is not yet 20. However, the surprisingly good results obtained justify further trials.

I should like to thank Dr. J. F. Chapman, of Glaxo, London, for making available the magnesium glutamate solutions.

-I am, etc.,

St. Bartholomew's Hospital, London E.C.1.

H. LEHMANN.

REFERENCES

${ }^{1}$ Greenberg, M. S., and Kass, E. H., Arch. intern. Med., 1958, 101, 355.

.$^{2}$ Nwokolo, C., W. Afr. med. J., 1960, 9, 194.

3 Scott, R. B., and Ferguson, A., Amer. J. Dis. Child., 1960, 100, 85 .

4 Allison, A. C., Clin. Sci., 1956, 15, 497.

5 Anstall, H. B., Huntsman, R. G., Lehmann, H., Hayward, G. H., and Weitzman, D., Lancet, 1959, 1, 814.

- Huntsman, R. G., Hurn, B. A. L., and Lehmann, H., J. clin. Path., 1960, 13, 99.

\section{Kerosene Poisoning}

SIR,-We were most interested to read your recent annotation on the subject of kerosene poisoning (January 26, p. 208). The problem of the management of these cases presents itself frequently in this hospital, based on the universal domestic use of kerosene by the local African population.

Since this hospital was opened in August, 1958, it has been standard practice to treat all cases of kerosene ingestion conservatively, omitting gastric lavage altogether. These patients are admitted to hospital for observation and are given prophylactic penicillin. During the period August, 1958, to December, 1962, 167 cases of kerosene poisoning have been admitted. Clinical or radiological evidence of pulmonary pathology occurred in 55 cases $(33 \%)$, but there was only one death. This occurred in a 2 -year-old child who was admitted in extremis, with evidence of gross pulmonary involvement. Death ensued one and a half hours after admission, and necropsy examination revealed pulmonary oedema.

We are at present engaged on a more detailed analysis of the above series, and hope to present this in due course. However, we feel that certain inferences can be made immediately. The comparatively low rate of pulmonary complications, together with the extremely low, or virtually non-existent, mortality rate, indicate that the decision to omit gastric lavage in treatment has been justified. While it is possible that lung changes can follow absorption of kerosene into the blood, we submit that the probable induction of vomiting by introducing a tube into the stomach of a young child can only increase the risks of aspiration pneumonia. -We are, etc.,
Mpilo Central Hospital,
Bulawayo,
Southern Rhodesia.
B. J. BALDAChin.
R. N. Melmed.

\section{Kidneys from Cadavers}

SIR,- In the treatment of infectious diseases active immunization is of little value when the disease is present. It must be given before exposure so that antibodies will be present in the body when exposure does occur. Conversely, it is perhaps logical to reduce the body's power to produce antibodies to foreign protein before this power is invoked by the introduction of a homograft.

The depression of lymphocytes and plasma cells, produced when cyclophosphamide is given to homograft hosts, is not instantaneous.

In your first leader of April 6, p. 899, you state "Cyclophosphamide is an unsatisfactory drug for inhibiting rejection of renal homografts in the dog." Reams, ${ }^{1}$ whom you quote, was less dogmatic, saying " . . . it was felt that cyclophosphamide in the dosage and method used for administration in this series had little overall effect in prolonging the survival time. .." (My italics.) He started to give his dogs cyclophosphamide at the time of (not before) the homograft.

Parsons et al. (April 6, p. 930) depressed the immunological response of their Case 2 (with radiation) before transplanting the cadaveric kidney and continued to depress it (with cyclophosphamide) after the operation. Preliminary depression of the immune mechanism of the body, whether it be with radiation or with cyclophosphamide, may be of the first importance.

The difference in duration of functional survival between Reams's dogs (average 12 days) and Parsons's Case 2 (16 weeks, at the time of publication of your leader, but there misprinted as " six weeks") may reflect not so much a species difference as a difference in design and method. There may be an optimum timing as well as an optimum dose.-I am, etc.,

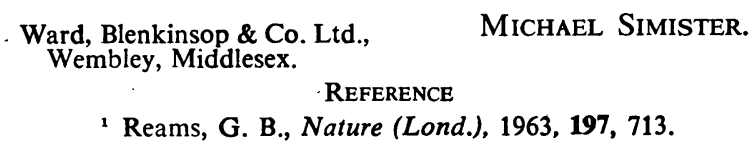

\section{Trial of Forceps}

SiR,-I refer to the letter from Mr. Ian Donaldson (April 13, p. 1022). Although his views on trial of forceps are obviously based on experience and critical thought, I am unable to agree with them.

I concede that vaginal examination without anaesthesia, when performed by a skilled person, will nearly always allow a correct decision to be made. In my experience, however, there have been a number of occasions when I have judged that forceps delivery would be extremely difficult or even impossible, and yet, at the trial under anaesthesia, it has proved to be remarkably easy. I have particularly in mind some cases of occipito-posterior position with the head arrested high in the pelvis. I am sure that I have avoided unnecessary caesarean sections in this way.

The knowledge that everything is prepared for caesarean section is a great comfort. It leads to calm and deliberate action as opposed to the fierce determination to deliver which, as Mr. Donaldson says, we have all either witnessed or experienced in the past.

I have never lost a baby from the effects of the anaesthesia and I have rarely had undue difficulty in delivering the head from the pelvis at caesarean section. For this purpose I have always found the right hand to be better than any instrument. I have never seen the Trendelenburg position used during caesarean section but I imagine it might interfere with lung expansion. If the uterus is tightly retracted around the foetus it may be necessary to ask the anaesthetist to relax it in order to disengage the head from the pelvis. This necessity can usually be foreseen.

It is, perhaps, relevant to add that most of the forceps deliveries in my department are performed under local 